\title{
PESSIMISTIC EXPLANATORY STYLE AND RESPONSE TO ILLNESS
}

\author{
Emily H. Lin and Christopher Peterson* \\ Department of Psychology, University of Michigan, 580 Union Drive, Ann Arbor, MI 48109-1346, U.S.A.
}

(Reccived 28 November 1989)

\begin{abstract}
Summary-Previous studies have shown that a pessimistic explanatory style is a risk factor for illness, but the factors linking explanatory style and illness arc unknown. One's charactcristic response to poor health may mediate this relationship. Perhaps pessimistic individuals act helplessly in the face of their symptoms, thereby exacerbating disease. In the present study, we investigated this possibility by asking 96 young adults to complete measures of explanatory style, habitual response to illness, and ways of coping during their most recent episode of illness. Subjects who explain bad events pessimistically (with internal, stable, and global causes) reported more frequent illnesses during the past year and rated their overall health more poorly than those who habitually favor external, unstable, and specific explanations. When ill, the pessimistic subjects were less likely than their optimistic counterparts to take active steps to combat their illness. Our results suggest that one pathway leading from pessimistic explanatory style to poor health is mundane: passivity in the face of disease.
\end{abstract}

Explanatory style is a cognitive personality variable defined as an individual's habitual way of explaining bad events (Peterson \& Seligman, 1984). Some people explain bad events fatalistically by pointing to causes within themselves that are chronic and pervasive (e.g. "I failed the midterm examination because I'm ignorant"). Other people favor more efficacious explanations: causes external to themselves that are highly circumscribed across time and situation (e.g. "I failed because the teacher was in a rare bad mood that afternoon"). We regard the former people as more pessimistic than the latter and believe that their explanatory style predisposes them to react to failure and frustration with passivity.

The reformulated learned helplessness model proposes that pessimistic explanatory style is a risk factor for depression (Abramson, Seligman \& Teasdale, 1978). Recent research has additionaily documented a variety of other negative outcomes, like poor work performance (Seligman $\&$ Schulman, 1986), academic failure (Peterson \& Barrett, 1987), and athletic setbacks (Peterson, 1990).

Poor health is one of the intriguing consequences recently attributed to pessimistic explanatory style. Studies have shown, for instance, that people who explain bad events in pessimistic fashion are more likely than optimistic individuals to fall ill, to visit physicians, to show faulty immune function, and even to die young (Peterson, 1988; Peterson \& Bossio, 1990; Peterson \& Seligman, 1987; Peterson, Seligman \& Vaillant, 1988).

These studies are exciting because they suggest that a psychological variable indeed influences physical well-being (cf. Angell, 1985), and the notion of explanatory style is in keeping with more general discussions of the association between pessimism and poor health (Friedman \& BoothKewley, 1987; Jemmott \& Locke, 1984). Even so, results to date are preliminary. Although a link seems to exist between explanatory style and illness, the nature of the pathway between the two is unknown.

The purpose of the present investigation was to look at one of the possible links between explanatory style and illness. Could it be that pessimistic people who fall ill are less likely than their optimistic counterparts to take care of themselves, thereby exacerbating their initial illness? Because fatalistic people see no contingency between actions and outcomes (Seligman, 1975), they may become passive in the face of illness or its warning signs.

We studied mostly healthy young adults. $S$ s completed a questionnaire assessing their explanatory style (Peterson \& Villanova, 1988). Then they described their habitual response to illness. How likely were they to take active steps in order to feel better, like changing their diet, taking vitamins, and sleeping more? They related how effective they perceived each response to be. Finally, $S \mathrm{~s}$

*To whom all correspondence should be addressed. 
responded to a version of the Ways of Coping questionnaire (Lazarus \& Folkman, 1984) in terms of their most recent episode of serious illness. This questionnaire was scored for 'efficacious' vs 'helpless' responses. We hypothesized that pessimistic $S$ s, those who explain bad events with internal, stable, and global causes, would be more likely than optimistic $S$ s, those who favor external, unstable, and specific explanations, to respond passively to illness.

\section{METHOD}

\section{Subjects and procedure}

Our research participants were 96 young adults ( $45 \mathrm{men}, 51$ women) enrolled in introductory psychology courses at the University of Michigan, whose participation fulfilled a course requirement. Questionnaires were administered to groups of $S \mathrm{~s}$ in single sessions.

\section{Questionnaires}

In order, the questionnaires completed by the research participants were as follows:

Questions about physical health. Ss answered four questions about their health status:

(a) In the past 12 months, how many different times were you ill?

(b) In the past 12 months, how many different times did you visit a physician for diagnosis and/or treatment of all illness (do not include injuries like a broken leg)?

(c) Are you ill right now? definitely no $(=1)$ maybe $(=2)$ definitely yes $(=3)$

(d) On the whole, how would you rate your physical health compared to others your age? (from $1=$ poor, to $7=$ excellent)

Expanded Attributional Style Questionnaire. Peterson and Villanova (1988) recently described the Expanded Attributional Style Questionnaire (EASQ), which was used in this study to measure explanatory style. This questionnaire presents $S$ s with hypothetical events involving themselves (e.g. you go out on a date, and it goes badly). They are asked to provide the 'one major cause' if this event actually happened, and then to rate their provided cause along 7-point scales according to its internality, stability, and globality. These ratings are averaged across events and across dimensions to yield an overall score of explanatory style, from optimistic to pessimistic. The EASQ has greater internal consistency than its previous version, because it is based on 24 (as opposed to 6) bad events (cf. Peterson, Semmel, von Baeyer, Abramson, Metalsky \& Seligman, 1982). The reliability of the EASQ in the present sample, estimated by coefficient $\alpha$, was 0.86 .

Response to illness. This questionnaire measures the degree to which individuals take active steps when ill in order to feel better. Through pilot work, we identified 18 different behaviors that college students sometimes perform when faced with illness (see Table 1). For each behavior, $S$ s are asked to use a 7 -point scale (from $1=$ never, to $7=$ always) to indicate the extent to which they engage in it when ill in order to relieve symptoms or make them go away. Ratings are averaged to provide an overall measure of active versus passive response to illness. The reliability of this composite in the present sample, estimated by coefficient $\alpha$, was 0.75 .

Table 1. Habitual responses to illness

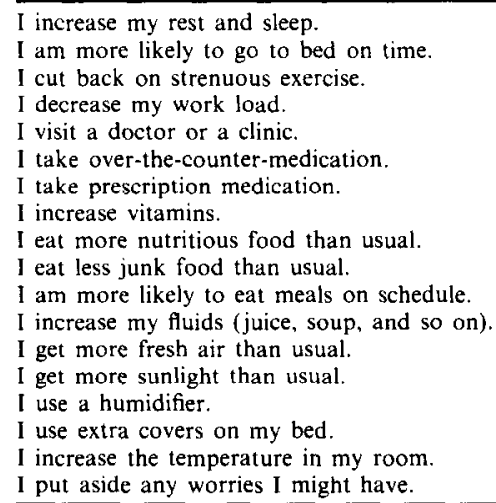


This questionnaire also presents $S \mathrm{~s}$ with the same 18 behaviors and asks them to rate each according to how effective they believe it usually is in relieving symptoms of illness or making them go away (from $1=$ not effective, to 7 =quite effective). These ratings are averaged, and the reliability of this composite in the present sample was 0.84 .

Ways of coping. The questionnaire developed by Lazarus and Folkman (1984) to measure people's appraisals of stressful events and how they cope with them was adapted for the present study. $S$ s are given these instructions:

The purpose of this questionnaire is to find out what goes on when people are ill. Of course they feel physically uncomfortable, but often they are troubled in other ways as well, because illness creates difficulties for them. We want to know about the difficulties you faced the last time you were ill and what if anything you did about these difficulties.

Take a few moments and think about the last time you were ill enough that it created problems or hassles for you in your everyday life. Describe what happened. Include details such as the place, who was around, what you did, and what made it important for you. Don't worry about writing a complete essay. Just jot down the things that come to you as you remember the situation.

$S$ s describe this episode of illness in writing. Then they are given these instructions:

Besides the fact that you felt physically uncomfortable, what else was going on in this situation that made it difficult? What was at stake for you? Below is a list of some reasons for being troubled by situations. Please look down the list and check off the ones that applied to you the last time you were ill.

Following are 10 possible reasons that someone might be distressed because of illness: frustration; concern about doing well; disappointment with a person; being criticized or rejected; fighting or arguing; dealing with a difficult person; bothersome conscience; too much to do; losing something or someone; and preparing for a big change.

Finally, $S$ s are asked to think further about this episode of illness, and indicate by checking 'yes' or 'no' whether or not they performed each of 68 different behaviors at that time. Our interest was directed specifically to 9 items reflecting a 'helpless' response to illness and 18 items reflecting an 'efficacious' response (see Table 2). These items were selected on an a priori basis, reflecting a

Table 2. Ways of coping with illness

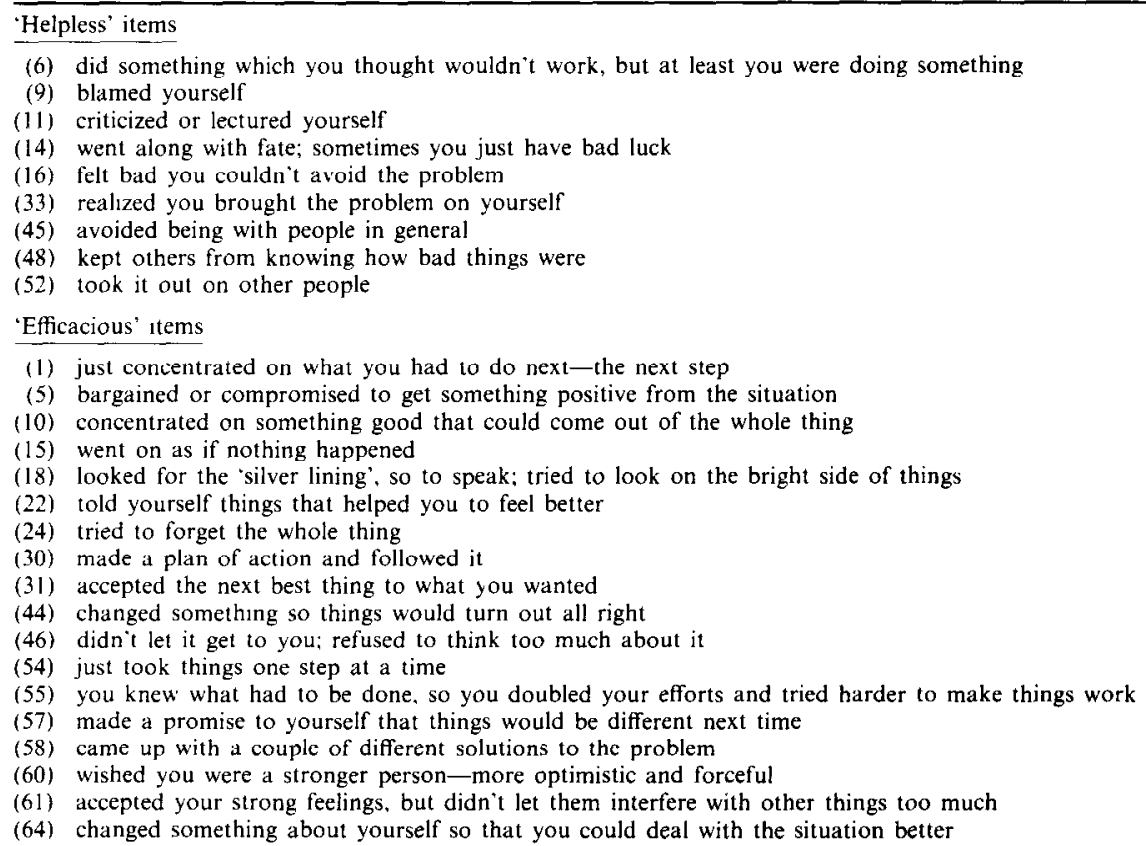




\begin{tabular}{lcc}
\multicolumn{3}{c}{ Table 3. Means of measures $(n=96)$} \\
\hline Measure & Mean & SD \\
\hline Explanatory style & 4.35 & 0.48 \\
Times ill & 2.89 & 1.82 \\
Doctor visits & 1.38 & 1.70 \\
Ill now? & 1.43 & 0.73 \\
Overall health & 5.51 & 1.06 \\
Habitual response & 3.99 & 0.75 \\
Perceived effectiveness & 4.76 & 0.84 \\
Efficacious coping & 40.19 & 3.58 \\
\hline
\end{tabular}

conception of helplessness not only as entailing emotional, motivational, and cognitive deficits (Seligman, 1975) but also more recent characterizations of helpless individuals as socially inept (Peterson, Colvin \& Lin, 1989), ruminative (Atlas \& Peterson, 1989), and unable to accommodate themselves to events (Rothbaum, Weisz \& Snyder, 1982).

'Yes' answers are scored 2, and 'no' items are scored 1 . A composite is formed by summing these items (reverse scoring for 'helpless' responses), yielding scores that can range from 27 (extremely helpless) to 54 (extremely helpless) to 54 (extremely efficacious). The reliability of this composite in the present sample was 0.56 .

\section{RESULTS}

Table 3 presents the means and standard deviations of the major measures. Sex of the $S$ was associated with only one of these measures; females rated their overall health more negatively than did males $(5.22$ vs $5.84, t=3.03, P<0.003)$. Because sex of the $S$ showed no relationship to explanatory style or to response to illness, subsequent data analyses collapse across sex.

Explanatory style and illness. Pessimistic explanatory style was positively correlated with the number of times $S$ s reported being ill during the past year $(r=0.27, P<0.01)$ and negatively correlated with their perception of their health as excellent $(r=-0.18, P<0.10)$. There was a weak tendency for pessimistic explanatory style to be associated with more doctor visits during the past year $(r=0.15, P<0.15)$. Explanatory style was not related to whether the $S$ s reported a current illness $(r=0.00, \mathrm{NS})$.

Explanatory style and habitual response to illness. Pessimistic explanatory style was negatively correlated with active attempts to relieve symptoms when ill $(r=-0.17, P<0.10)$. Explanatory style was not related to the perceived effectiveness of these attempts $(r=-0.04$, NS). Active attempts to relieve symptoms were positively correlated with the perceived effectiveness of these attempts $(r=0.54, P<0.001)$.

Explanatory style and coping with illness. The written descriptions by the $S$ s were coded for type of illness. Table 4 shows that the vast majority of $S$ s described an infectious illness, usually a cold or the flu but occasionally a strep throat or mononucleosis.

Only one of the 10 possible reasons why illness might be stressful was associated with explanatory style. Pessimistic individuals, when ill, were more likely to report being afraid that they would be criticized or rejected by others $(r=0.25, P<0.02)$. In the present sample, $22 \%$ of the $S$ s expressed this fear.

Pessimistic explanatory style was negatively correlated with efficacious coping during $S \mathrm{~s}^{\prime}$ most recent episode of illness $(r=0.36, P<0.001)$. $S \mathrm{~s}$ ' habitual response to illness was associated with efficacious coping during their most recent episode of illness $(r=0.23, P<0.02)$, as were their perceptions of the effectiveness of their habitual responses to illness $(r=0.22, P<0.03)$.

Table 4. Types of illnesses described $(n=96)$

\begin{tabular}{lr}
\hline Type of illness & $n$ \\
\hline A cold or the flu & 72 \\
Other infectious illness (e.g. mononucleosis. strep throat) & 17 \\
Back injury & 1 \\
Hypertensive attack & 1 \\
Kidney failure & 1 \\
Migraine & 1 \\
Sea sickness & 1 \\
Did not say & 2 \\
\hline
\end{tabular}




\section{DISCUSSION}

Our results provide some evidence about what may link pessimistic explanatory style to poor health. Individuals who explain bad events with internal, stable, and global causes were less likely than individuals who explain events optimistically to take active steps to combat illness once it develops. In other words, pessimistic explanatory style may predispose one to act helplessly in the wake of a bad event like illness. Repeated helplessness concerning health care may start the pessimistic individual into a downward spiral toward worsening health (Peterson et al., 1988).

The conclusion that neglected health care may partly mediate the pessimism-illness link is plausible yet mundane: mother and father told us this repeatedly while we were growing up. We therefore doubt that any will find our results and conclusions controversial. Perhaps the legitimate role of psychologists in the prevention and treatment of poor health can be readily seen.

In particular, the therapy implications of the present findings are clear. Health promotion programs all face a dilemma: the payoff is distant for people who watch their diet, curtail cigarettes. or sleep regularly. Epidemiological studies show that habits reliably predict morbidity and mortality, but the relevance of these relationships to the individual must be accepted by him or her on faith. No wonder that pessimistic people do not respond actively to symptoms of illness. Changing people's pessimistic explanatory style and/or passive behavior in the face of illness should promote their health.

We are not claiming that the active responses chosen for study here were necessarily cures for the colds and flus from which most of our $S$ s suffered. We suspect they at best provided symptomatic relief. Regardless, our arguments do not hinge on the medical validity of these responses so much as on the fact that optimistic $S$ s undertook them when ill, whereas pessimistic $S$ s did not. We extrapolate to conclude that at some point in life, a pessimistic individual will refrain from a truly helpful response when faced with illness.

An ostensible puzzle in the present data is that explanatory style was not related to the perceived effectiveness of 'active' responses to illness. The straight-forward prediction from helplessness theory is that explanatory style should be linked to perceived ineffectiveness of responding (Peterson \& Seligman, 1984). Future research needs to take a closer look at $S$ s' beliefs. Perhaps Bandura's (1986) distinction between outcome expectancies ("This response is effective") and efficacy expectancies ("I can perform that response") would be useful.

In a previous study, we indeed found that pessimistic $S$ s reported low self-efficacy with respect to health-promoting behaviors (Peterson, 1988). It may well be the case that pessimistic explanatory style leads to passivity not through decreased outcome expectancies but via decreased efficacy expectancies. If this is the case, helplessness theory needs to be modified (Seligman, 1975).

That pessimistic $S \mathrm{~s}$ feared criticism or rejection by others when ill is intriguing because it converges with other data we have recently gathered that places 'helplessness' explicitly in a social context (Peterson et al., 1989). Two findings from this line of work should be noted. First, people regarded by their friends as prototypically helpless tend to involve others in their plight, constantly asking for assistance in doing things. Second, as these requests increase, their friends become ever less willing to help. 'Helpless' behavior may start out as instrumental, but eventually becomes ineffective because it turns away other people. Again, a modification of helplessness theory may be needed to accommodate these possibilities.

We do not believe that passive responses to illness are the only mediator between explanatory style and poor health. The relationships obtained in this study are of modest magnitude. implying that the route between psychological factors like explanatory style and physical well-being is over-determined (Peterson \& Bossio, 1990). In particular, when 'illness' is operationalized in nonspecific terms, as done here, there probably exist many routes to poor health. We plan eventually to look simultaneously at specific types of illness and several possible mediators. Perhaps explanatory style more readily predisposes some illnesses than others. Perhaps its mode of operation differs from illness to illness.

The present study has obvious shortcomings. We relied exclusively on self-report measures. It is difficult to see how responses sets like complaining could account for all the patterns obtained here (Costa \& McCrea, 1987), but future research should use multiple measures (see Peterson \& Seligman, 1987). We used a cross-sectional design, not a longitudinal one, so we cannot conclude 
with certainty that explanatory style preceded the behaviors about which we asked (see Peterson, 1988; Peterson et al., 1988). Finally, all of our $S$ s were healthy young adults, and generalization to an older and/or less healthy population must be cautious.

Despite these shortcomings, the present study expands and clarifies the empirical support for the reformulated model of learned helplessness by suggesting that explanatory style leads to passivity following a bad event (illness). Perhaps this route entails decreased efficacy expectancies. Typical research in the helplessness tradition can be faulted for neglecting to take into account bad events, and further for measuring depression rather than helpless behavior per se. At least some of the controversy surrounding the reformulated model stems from inadequate tests.

Our discussion goes beyond the data we report. We nevertheless think that the present findings are important precisely because they spark such discussion. They suggest that a possible link between explanatory style and health is one's behavior when he or she falls ill. By implication, they remind the cognitively-oriented health promoter not to neglect mundane behavior change.

Acknowledgements This paper is based on an honors thesis completed by Emily $\mathrm{H}$. Lin under the supervision of Christopher Peterson. We wish to thank Daniel Weintraub and Neff Walker for their help. We also thank Lisa M. Bossio for her editorial assitance in preparing this article.

\section{REFERENCES}

Abramson, L. Y.. Seligman, M. E. P. \& Teasdale, J. D. (1978). Learned helplessness in people: Critique and reformulation. Journal of Abnormal Psychology, 87, 49-74.

Angell, M. (1985). Disease as a reflection of the psyche. The New England Journal of Medicine, 3/2, 1570-1572.

Atlas, G. D. \& Peterson, C. (1989). Explanatory style among harness racing bettors. Unpublished manuscript, University of Michigan

Bandura, A. (1986). Social foundations of thought and action. Englewood Cliffs, N.J.: Prentice-Hall.

Costa, P. T. \& McCrae, R. R. (1987). Neuroticism, somatic complaints, and disease: Is the bark worse than the bite? Journal of Personality, 55, 299-316.

Friedman, H. S. \& Booth-Kewley, S. (1987). The 'disease-prone personality': A meta-analytic view of the construct. American Psychologist, 42, 539-555.

Jemmott, J. B. \& Locke, S. E. (1984). Psychosocial factors, immunologic mediation, and human susceptibility to infectious diseases: How much do we know? Psychological Bulletin, 95, 78-108.

Lazarus, R. S. \& Folkman, S. (1984). Stress, appraisal, and coping. New York: Springer

Peterson, C. (1988). Explanatory style as a risk factor for illness. Cognitive Therapy and Research, 12. 117-130.

Peterson, C. (1990). Explanatory style in the classroom and on the playing field. In Graham, S. \& Folkes, V. S. (Eds), Advances in applied social psychology (Vol. 5). Hillsdale, N.J.: Erlbaum.

Peterson, C. \& Barrett, L. C. (1987). Explanatory style and academic performance among university freshmen. Journal of Personality and Social Psychology, 53, 603-607.

Peterson, C. \& Bossio. I. M. (1990). Optimism and health. New York: Free Press.

Peterson. C. \& Seligman, M. E. P. (1984). Causal explanations as a risk factor for depression: Theory and evidence. Psychological Review. 91, 347-374.

Peterson. C. \& Seligman. M. E. P. (1987). Explanatory style and illness. Journal of Personality, 55, 237-265.

Peterson, C. \& Villanova, P. (1988). An Expanded Attributional Style Questionnaire. Journal of Abnormal Psychology.97. 87-89.

Peterson, C., Colvin, D. \& Lin, E. H. (1989). Explanatory style and helplessness. Unpublished manuscript, University of Michigan.

Peterson, C., Seligman, M. E. P. \& Vaillant, G. E. (1988). Pessimistic explanatory style is a risk factor for physical illness: A thirty-five year longitudinal study. Journal of Personality and Social Psychology, 55, 23-27.

Peterson, C., Semmel, A., von Baeyer, C., Abramson, L. Y., Metalsky, G. I. \& Seligman, M. E. P. (1982). The Attributional Style Questionnaire. Cognitive Therapy and Research, 6, 287-299.

Rothbaum, F., Weisz, J. R. \& Snyder, S. S. (1982). Changing the world and changing the self: A two-process model of perceived control. Journal of Personality and Social Psychology, 42, 5-37.

Seligman. M. E. P. (1975). Helplessness: On depression, development, and death. Freeman: San Francisco.

Seligman, M. E. P. \& Schulman, P. (1986). Explanatory style as a predictor of productivity and quitting among life insurance agents. Journal of Personality and Social Psychology, 50, 832-838. 